\title{
Maintenance treatment with progesterone gel and the gel base delayed preterm birth more effectively than intravenous tocolysis alone - a randomized controlled trial
}

\author{
Ylva Vladic Stjernholm ( $\nabla$ ylva.vladic-stjernholm@sll.se ) \\ Karolinska University Hospital \\ Giovanna Marchini \\ Karolinska University Hospital \\ Tomislav Vladic \\ Karolinska University Hospital
}

\section{Research Article}

Keywords: Cervical ripening, chorioamnionitis, preterm birth, preterm labor, progesterone.

Posted Date: March 17th, 2021

DOl: https://doi.org/10.21203/rs.3.rs-290118/v1

License: (c) (1) This work is licensed under a Creative Commons Attribution 4.0 International License.

Read Full License 
Maintenance treatment with progesterone gel and the gel base delayed preterm birth more effectively than intravenous tocolysis alone - a randomized controlled trial

Ylva Vladic Stjernholm ${ }^{1}$, Tomislav Vladic ${ }^{1}$, Giovanna Marchini ${ }^{2}$

Department of Women's and Children`s Health, Obstetric Unit ${ }^{1}$, Neonatal Unit Astrid Lindgren's Children's Hospital ${ }^{2}$, Karolinska University Hospital and Karolinska Institute, SE-171 76 Stockholm, Sweden

Corresponding author: Dr Ylva Vladic Stjernholm, Department of Women’s and Children's Health, Karolinska University Hospital and Karolinska Institutet, SE-171 76 Stockholm, Sweden e-mail: ylva.vladic-stjernholm@sll.se

Key words: Cervical ripening, chorioamnionitis, preterm birth, preterm labor, progesterone.

\section{List of abbreviations}

BW Birth weight; CL Cervical length; IVH Intraventricular hemorrage; MMP Matrix metalloproteinase enzyme; NEC Necrotizing Enterocolitis; NICU Neonatal Intensive Care Unit; PTB Preterm Birth, PTL Preterm Labor, RDS Respiratory Distress Syndrome; ROP Retinopathy of Prematurity; SPA Spontaneous Abortion, sPTB Spontaneous Preterm Birth. 


\begin{abstract}
Introduction The aim was to evaluate the effect of maintenance treatment with progesterone gel compared to the gel base in delaying preterm birth among women with spontaneous preterm labor. Materials and Methods A randomized controlled trial in Sweden in $2009-18$. Women with spontaneous preterm labor were randomized to daily progesterone gel $90 \mathrm{mg}(\mathrm{n}=29)$ or gel base doses $(\mathrm{n}=29)$ after intravenous tocolysis.
\end{abstract}

Results The latency to delivery was $58 \pm 34$ days with progesterone gel and $64 \pm 51$ days with gel base $(p=0.83)$, compared to 2 days after intravenous tocolysis alone (both $p<0.001)$. The rate of preterm birth before 34 weeks was $34 \%$ after progesterone gel and $38 \%$ after gel base $(p=0.34)$. The composite neonatal morbidity $(\mathrm{p}=0.65)$ and neonatal intensive care unit admission $(\mathrm{p}=0.12)$ did not differ between the groups.

Conclusion Preterm birth was delayed more effectively after both progesterone and gel base compared to intravenous tocoylsis alone, suggesting an effect of the gel base. We conclude, that the acidic gel base reinforced the physiological barrier at the uterine cervix, which counteracted ascending pathogen invasion and thereby delayed preterm birth. 


\section{Introduction}

The global rate of preterm birth (PTB), the main cause of all neonatal, infant and child mortality up to 5 years age, is still $10 \%$ [1]. The multifactorial risk factors include demographic and socioeconomic factors such as psychosocial stress, malnutrition, low and high maternal age, multiple pregnancy, decidual bleeding, and pathogen invasion from the skin and gastrointestinal microbiome that cause uterine infection and inflammation of the fetal membranes and amniotic fluid [2-7]. Current tocolytic treatments with an oxytocin receptor antagonist, a $\beta 2$-adrenergic receptor agonist, magnesium sulfate, a non-steroid anti-inflammatory drug (NSAID) or a calcium blocker do not prevent PTB, but are used to delay delivery for at least $48 \mathrm{~h}$ to optimize the effect of antenatal corticosteroids for fetal lung maturation and allow for transport to a tertiary hospital with Neonatal Intensive Care Unit (NICU) expertise [8]. A cervical length $(\mathrm{CL}) \leq 25 \mathrm{~mm}$ at midgestation is regarded as a primary predictor for PTB [9].

Despite the multifactorial causes behind PTB, a cervical connective tissue remodeling precedes both preterm and term labor. This remodeling is characterized by an increased density of macrophages in the cervical tissue, release of proinflammatory cytokines and prostaglandin E, a functional progesterone withdrawal, activation of metalloproteinase (MMP) enzymes, a changed proteoglycan composition with dispersion of collagen fibrils, and collagen degradation. These biochemical events allow for cervical effacement and dilatation, which is a prerequisite for delivery [4-7, 10].

Although progesterone is regarded as the primary pregnancy maintenance hormone, reports on prophylactic treatment with bioidentical progesterone or synthetic progestins such as $17 \alpha-$ hydroxyprogesterone caproate (17OH-PC) in delaying PTB are inconclusive [2]. Bioidentical progesterone has no androgenic effects that might affect the lipid metabolism or harm the fetus. In clinical practice, oral progesterone is poorly absorbed because of the liver metabolism, daily progesterone injections would be painful, and a transdermal progesterone preparation has not been available in obstetrics. Vaginal mode of treatment is therefore used [2, 11]. Prophylactic treatment 
with progesterone from the second trimester in asymptomatic women with a medical history of previous PTB or a short CL, which is recommended by the International Federation of Gynecology and Obstetrics (FIGO), is effective according to some studies but the largest studies [2, 12, 13]. Extensive screening programmes are needed to evaluate prophylactic strategies since only $10-20 \%$ of women with spontaneous PTB have a previous PTB [2,9] and only $1 \%$ of asymptomatic women have a CL $\leq 25 \mathrm{~mm}$ in the second trimester [14].

\section{Aim}

The aim was to evaluate the effect of maintenance treatment with progesterone gel compared to the gel base in delaying PTB among women with early spontaneous preterm labor (sPTL).

\section{Materials and methods}

\section{Study design}

This trial was conducted at the Obstetric Unit, Department of Women's and Children's Health, Karolinska University Hospital and Karolinska Institutet, Stockholm, Sweden between December 1, 2009 and January 31, 2018

\section{Ethics approval and registration}

Ethics approval was obtained from the Regional Ethics Board for Medical Sciences in Stockholm September 5, 2007, No 2007-311-31. It was registered at the European Union Drug Regulating Authorities Clinical Trials (EudraCT), that participates in the World Health Organization (WHO) International Clinical Trial Registry Platform 01/09/2007, No 2007-003348-31. It was approved by the Swedish Medical Products Agency 15/05/2008, No 151:2008/30388. All treatments were performed according to the relevant clinical guidelines and regulations.

\section{Study participants}

Healthy women with singleton pregnancy and PTL after $24+0$ gestational weeks were included, see Figure 1. Informed consent was obtained from all study participants. The maintenance treatments with progesterone $(n=29)$ or the gel base $(n=29)$ were initiated after treatment with intravenous tocolysis 
according to standard clinical routines. Preterm labor was uterine contractions $\geq 2 / 10$ min for $>30$ min monitored by cardiotocography (CTG), recorded in electronic obstetric records (Obstetrix ${ }^{\circledR}$ Cerner $\mathrm{AB}$, Stockholm, Sweden) and resulting in a $\mathrm{CL}<25 \mathrm{~mm}$ determined sonographically by a specialist in obstetrics and gynecology due to standardized criteria. In all years studied $2009-18$, intravenous tocolysis was a bolus dose of the oxytocin receptor antagonist atosiban $\left(\right.$ Tractocile $^{\circledR}$, Ferring Pharmaceuticals, Sweden) $6.75 \mathrm{mg}$ followed by infusion of $300 \mu \mathrm{g} / \mathrm{min}$ during 3 hours and thereafter $100 \mu \mathrm{g} / \mathrm{min}$ until 48 hours. Alternatively, a $\beta 2$-adrenergic receptor agonist terbutaline (Bricanyl ${ }^{\circledR}$, AstraZeneca PLC, Great Britain) $5 \mu \mathrm{g} / \mathrm{mL}$ was given for 48 hours according to the individual physician’s choice. All women received two doses of betamethasone (Betapred ${ }^{\circledR}$, Swedish Orphan Biovitrum AB) 12 mg intramuscularly 24 hours apart for fetal lung maturation. Prophylactic antibiotics were not given to women with intact fetal membranes. Intrapartal prophylaxis with benzylpenicillin 3 g every 6 hours was given during active labor before 37 weeks.

The participants were blindly randomised by a computerized system using closed envelopes to maintenance treatment with daily vaginal progesterone gel (Crinone ${ }^{\circledR} 90 \mathrm{mg} /$ dose, Merck KGaA, Germany) or the gel base (Replens ${ }^{\circledR}$, CampusPharma AB, Sweden). It was not possible to blind the gel packages due to practical reasons. Thus, a semi-blinded design was obtained where the randomization process was blinded but not the treatments. Inclusion criteria were singleton pregnancy, intact fetal membranes, and PTL resulting in a CL $<25 \mathrm{~mm}$. Exclusion critera were multiple pregnancy, ruptured fetal membranes, cervical dilatation, cervical cerclage, signs or symptoms of chorioamnionitis, previous uterine surgery, prophylactic progesterone treatment, intercurrent maternal diseases, pregnancy complications such as preeclampsia or gestational diabetes, intrauterine fetal growth restriction or fetal malformations.

The maintenance treatment with progesterone or the gel base continued until $34+0$ weeks, rupture of the fetal membranes or delivery whatever occurred first. All women were seen weekly by an obstetrician at the hospital after discharge. 


\section{Outcomes}

The primary outcome latency to delivery was the time between the first gel dose and childbirth. The secondary outcomes were delivery within 7 days, early spontaneous PTB (sPTB) $<34$ weeks, late sPTB $<37$ weeks, neonatal birth weight (BW), composite neonatal morbidity, NICU admission and length of NICU stay. Composite neonatal morbidity was Apgar score $<7$ at $5 \mathrm{~min}$, the incidence of neonatal respiratory distress syndrome (RDS), intraventricular hemorrage (IVH), necrotizing enterocolitis (NEC) and sepsis $\leq 7$ days, taken together with retinopathy of prematurity (ROP) and neonatal death during the NICU stay. Neonatal RDS was defined by clinical diagnosis of type I RDS and a requirement of oxygen therapy for at least $24 \mathrm{~h}$. Maternal adverse effects such as fatigue, headache, or intrahepatic cholestasis were monitored.

\section{Statistics}

Based on results from previous studies [15] our hypothesis was the latency to delivery would be $30 \%$ longer in the progesterone group compared to the control group. According to a power analysis, a sample size of $\mathrm{n}=29$ in each group would be needed when aiming at a significance of $5 \%$ and power of $80 \%$ [16]. Continuous data were analyzed using Mann Whitney U-test. Continuous data were presented as mean \pm standard deviation $(\mathrm{SD})$. Categorical data were analyzed with $\mathrm{Chi}^{2}$-test and Fisher's exact test when appropriate. Confidence intervals and composite neonatal morbidity were analyzed with One way ANOVA. Categorical data were presented as numbers and percentages. A two-tailed $\mathrm{p}$ value $<0.05$ was considered significant.

\section{Results}

The trial character as a single center study with an aim to include the limited rate of $<1 \%$ of delivering women with extremely early PTL before 28 weeks, with the mentioned inclusion and exclusion criteria explains the duration of the study. 
Patient characteristics are shown in Table 1. Demographic maternal data were comparable between the groups. The participants in both groups had a medical history of a previous PTB in $25 \%$ and first or second trimester spontaneous abortion (SPA) in $25 \%$ (data not shown). The mean circulating level of the inflammatory marker C-reactive protein (CRP) at treatment initiation was $<10 \mathrm{mg} / \mathrm{L}$ and comparable between the groups (data not shown). The mean gestational age at inclusion was 26 weeks in both groups, where $82 \%$ of the participants were included between $24-27$ weeks and the remaining $8 \%$ between $28-31$ weeks. The CL (mean \pm SD) at treatment initiation was $11 \pm 5 \mathrm{~mm}$ in the progesterone group and $12 \pm 5 \mathrm{~mm}$ in controls $(\mathrm{p}=0.37)$.

Maternal data are shown in Table 2. The latency to delivery (mean \pm SD) was $58 \pm 34$ days in the progesterone group and $64 \pm 51$ days in the gel base group $(\mathrm{p}=0.83)$. The rate of early PTB $<34$ weeks was $34 \%$ in the progesterone group and $38 \%$ in the control group $(\mathrm{p}=0.32)$. The rate of late PTB $<37$ weeks was $52 \%$ after progesterone and $45 \%$ after gel base $(\mathrm{p}=0.65)$. The compliance rates were high. One participant in the progesterone and gel base groups each had their treatment interrupted before 34 weeks after referral to another hospital, and both gave birth after 37 weeks. One woman in the progesterone group, who had an emergency cervical cerclage on maternal request after inclusion in the study, continued her progesterone treatment and gave birth at 34 weeks. No severe maternal side effects such as headache or intrahepatic cholestasis were reported. One woman in the progesterone group reported fatigue.

Neonatal data are shown in Table 3. The BW (mean \pm SD) was $2471 \pm 1078 \mathrm{~g}$ in the progesterone group and $2452 \pm 1054$ in the gel base group $(\mathrm{p}=0.84)$. The composite neonatal morbidity was $72 \%$ $(21 / 29)$ in the progesterone group and $65 \%(19 / 29)$ in the control group $(\mathrm{p}=0.65)$. The rate of NICU admission was $31 \%$ (9/29) after progesterone and $24 \%$ (7/29) after gel base, whereas the mean length of NICU stay was 10 days in both groups $(\mathrm{p}=0.59)$. Two neonatal deaths during the NICU stay occured in the progesterone group and one in the gel base group. These neonatal deaths were caused by postnatally diagnosed severe malformations and chromosomal aberrations and were not associated with the different treatments. 


\section{Discussion}

We have evaulated the effect of maintenance treatment with vaginal progesterone gel compared to the gel base in delaying SPTB among women with singleton pregnancy and early PTL. Treatment with progesterone gel and gel base were initiated after intravenous tocolysis according to standard clinical routines.

\section{Main findings}

The main findings of this study were that the primary outcome latency to delivery was comparable after maintenance treatment with progesterone gel and the gel base. Also, the secondary outcomes rate of delivery within 7 days, early sPTB $<34$ weeks, late sPTB $<37$ weeks, mean neonatal BW, composite neonatal morbidity, NICU admission, and length of NICU stay did not differ between the groups. The treatments were safe with regard to maternal, fetal and neonatal health in a short perspective, since no severe adverse effects were recorded among the participating women or their neonates until discharge from the hospital.

It was noted, that the latency to delivery in both groups in this trial were longer than the mean latency to delivery 2 days among women with singleton pregnancy, identical inclusion criteria and early PTL, who received intravenous tocolysis alone according to standard clinical routines during the years studied $2009-18$. The rate of SPTB $<34$ weeks among women who received intravenous tocolysis alone was $100 \%$. Among their newborns the rate of NICU admission was $100 \%$, and the mean length of NICU stay was 70 days $(\mathrm{p}<0.0001$ for latency to delivery and NICU stay between progesterone and gel base groups and standard clinical routines; $\mathrm{p}=0.02$ for $\mathrm{sPTB}<34$ weeks between progesterone and gel base groups and standard clinical routines. Clinical communication).

\section{Clinical implications}

The present results suggest that the effect was attributed to the gel base, rather than progesterone. The gel base is an acidic emulsion of oil and water. The physiological acidic milieu with a low $\mathrm{pH}<4.5$ at 
the uterine cervix constitutes a biochemical barrier against ascending pathogen invasion from the skin and gastrointestinal microbiomes, and protects the pregnancy from uterine infection and inflammation which are known triggers of PTL. The vaginal microbiome undergoes significant changes during pregnancy resulting in a decrease in the vaginal $\mathrm{pH}$ [17]. Therefore, the acidic character of the gel base most likely reinforced the biochemical barrier at the uterine cervix, which counteracted pathogen invasion and PTL. The present results were in accordance with reports on uterine infection due to pathogen invasion from the skin and gastrointestinal microbiomes as an ethiology behind $30-60 \%$ of all early PTB [2]. The present findings were also in agreement with results from a study showing that the gel base exerts anti-inflammatory effects, decreases the cervical collagen metabolizing enzyme MMP-13, and delays sPTB [18].

Randomized controlled studies on maintenance treatment with vaginal progesterone gel after the onset of PTL have been warranted [19]. Only a few reports on this topic have been published. Two trials report longer latency do delivery after vaginal progesterone compared to no treatment $[15,20]$, one reports longer latency to delivery after vaginal progesterone compared to placebo [21], and one reports no reduction in PTB after vaginal progesterone or intramuscular progestin $17 \mathrm{OH}-\mathrm{PC}$ compared to no treatment [22].

The discrepancies between the present results and previous findings could be explained by the different study designs. Participants in the present trial were included at mean 26 weeks in contrast to 31 week or more $[15,20-21]$ and 28 weeks or more [22] in previous studies. Spontaneous preterm labor was uterine contractions $\geq 2$ per $10 \mathrm{~min}$ for more than $30 \mathrm{~min}$ resulting in a sonographically determined CL $<25 \mathrm{~mm}$ without cervical dilatation in the present and one of the previous studies [22], in contrast to cervical shortening and/or softening or dilatation [15], cervical softening, shortening at least by $50 \%$ and dilatation $<2 \mathrm{~cm}$ [20] or cervical dilatation and/or effacement [21] as determined by digital examination in other studies. Transvaginal sonography is recommended for CL assessment in women with PTL, and the accuracy of digital estimation of CL is questioned [13, 14]. Intravenous tocolysis in the present trial was an oxytocin receptor antagonist or a $\beta 2$-receptor agonist in contrast to 
magnesium sulfate in combination with ampicillin [15], a $\beta 2-$ receptor agonist [20], magnesium sulfate in combination with pethidine and ampicillin [21], an oxytocin receptor antagonist, a calcium blocker or a NSAID in earlier studies [22]. The maintenance treatment was progesterone gel $90 \mathrm{mg}$ in the present study, in contrast to vaginal progesterone suppositories $400 \mathrm{mg}$ [15] or $200 \mathrm{mg}$ [20-22] in earlier studies. Different bioavailability between the progesterone preparations could have contributed to the different results. However, the clinical effects are similar when vaginal progesterone gel is compared to a vaginal suppository for luteal phase support in early pregnancy [23].

\section{Strengths and limitations}

Strengths of this study were the randomized controlled design, the clear inclusion and exclusion criteria, the sonographical CL determination, and that all data were retrieved from original electronic obstetric records at one hospital. Limitations were the lack of double blinded design, the long duration of the study and the limited sample size, although it was adequate according to a power analysis regarding the primary outcome. It is possible also, that the mere inclusion in the study reduced chronic psychosocial stress, which is a risk factor of sPTB, and thereby delayed PTB [24-25].

\section{Conclusion}

The present results showed, that PTB was delayed more effectively among women who received progesterone gel or the gel base compared to intravenous tocolysis alone according to standard clinical routines, suggesting an effect of the gel base. We conclude, that the acidic gel base reinforced the physiological barrier at the uterine cervix, which counteracted ascending pathogen invasion and thereby delayed PTB. The present results suggest that non-hormonal agents that strengthen the cervical barrier can be useful for the prevention of PTB in clinical practice. 


\section{Acknowledgements}

We thank the women who participated in this trial, Therese Westerberg, nurse at the Neonatal Unit, for retrieving neonatal data, professor Lars Hagenäs, Endocrinology Unit, Astrid Lindgren`s Children`s Hospital for valuable comments when planning this study, and the staff at the Obstetric, Neonatal and Operative Units at the Karolinska University Hospital for constructive collaboration.

\section{Author contribution}

GM, YVS planned and designed the study and collected the material. GM, TV and YVS analysed the data, wrote and approved the manuscript.

\section{Conflicts of interests}

The authors declare that they have no conflicts of interests.

\section{Funding}

There was no funding.

\section{Data availability}

All data are preserved by the authors and available if requested. 


\section{References}

1. Chawanpaiboon S, Vogel JP, Moller AB, Lumbiganon P, Petzold M, Hogan D, et al. Global, regional and national estimates of levels of preterm birth in 2014: a systematic review and modeling analysis. The Lancet Global Health 2019; vol 7, E37 46.

2. Cobo T, Kacerovsky M, Jacobsson B. Risk factors for spontaneous preterm birth. Int J Obstet Gynecol 2020; 150: $17-23$.

3. Norman J. Progesterone and preterm birth. Obstet Gynecol 2020; 150: 24-30.

4. Vladic-Stjernholm Y Wang H, Stygar D, Ekman G, Sahlin L. Differential regulation of the progesterone receptor A and B in the human uterine cervix at parturition. Gynecol Endocrinol 2004;Jan18(1):41-6.

5. Abelin-Törnblom S, Dubicke A, Byström B, Chromek M, Brauner A, Ekman-Ordeberg G. Non-infected preterm parturition is related to increased concentrations of IL-6, IL-8 and MCP-1 in human cervix. J Reprod Biol Endocrinol 2005; 3:39.

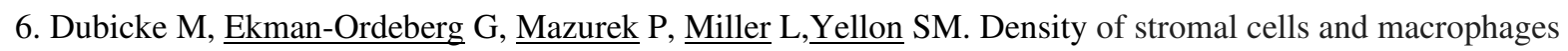
associated with collagen remodeling in the human cervix in preterm and term birth. J Reprod Sci 2016;23:595603.

7. Yellon SM, Dobyns AE, Beck HL, Kurtzmans JT, Garfield RE. Kirby MA. Loss of progesterone receptormediated actions induce preterm cellular and structural remodeling of the cervix and premature birth. PLoS ONE 2013;8(12): e81340.

8. Haas DM, Benjamin T, Sawyer R, Quinney SK. Short-term tocolytics for preterm delivery - current perspectives. International Journal of Women's Health 2014; 6 343-9. 
9. Iams JD, Goldenberg RL, Meis PJ, Mercer B, Moawad A, Das A, et al. The length of the cervix and the risk of spontaneous preterm delivery. National Institute of Child Health and Human Development Maternal Fetal Medicine. New Engl J Med 1996;334:567-72.

10. Vladic-Stjernholm Y, Stygar D, Månsson C, Masironi B, Åkerberg S, Ekman G, et al. Factors involved in the inflammatory events of cervical ripening in humans. J Reprod Biol Endocrinol 2004;2:74.

11. Schindler AE, Campagnoli C, Druckmann R, Huber J, Pasqualini JR, Schweppe KW, Thijssen JH. Classification and pharmacology of progestins. Maturitas 2008;61:171-80.

12. Norman JE, Marlow N, Messow CM, Shennan A, Bennett P, Thornton P, et al. Vaginal progesterone prophylaxis for preterm birth (the OPPTIMUM study): a multicentre, randomised, double-blind study. Lancet 2016;387:2106-16.

13. FIGO Working Group on best practice in maternal-fetal medicine. Best practice in maternal-fetal medicine. Int J Gynecol Obstet 2015:128:80-2.

14. Kuusela P, Jacobsson B, Söderlund M, Bejlum C, Almström E, Ladfors L, et al. Transvaginal sonographic evaluation of cervical length in the second trimester of asymptomatic singleton pregnancies, and the risk of preterm delivery. Acta Obstet Gynecol Scand 2015;94:598-607.

15. Borna S, Sahabi N. Progesterone for maintenance tocolytic therapy after threatened preterm labour: A randomised controlled trial. Austr New Zeal J Obstet Gynecol 2008;48:58-63.

16. Pocock SJ. Clinical trials (1984). Wiley \& Sons, New York, US.

17. Nuriel-Ohayon M, Neuman H, Koren O. Microbial changes during pregnancy, birth, and infancy. Front Microbiol 2016;7:1031 
18. Nold C, Jensen T, O`Hara K, Stone J, Yellon SM, Vells AT. Replens prevents preterm birth by decreasing type I interferon strengthening of the cervical epithelial barrier. Am J Reprod Immunol 2019;00:e13192.

19. Su L, Samuel M, Chong Y. Progestational agents for treating threatened or established preterm labour. Cochrane Database Syst Rev 2014, Issue 1. Art. No.: CD006770.

20. Arikan I, Barut A, Harma M, Harma IM. Effect of progesterone as a tocolytic and in maintenance therapy during preterm labor. Gynecol Obstet Invest 2011;72:269-73.

21. Sharami SH, Zahiri Z, Shakiba M, Milani F. Maintenance therapy by vaginal progesterone after threatened idiopatic preterm labor: a randomized placebo-controlled double-blind trial. Int J Fertil Steril 2010;4:45-50.

22. Facchinetti F, Vergani P, Di Tommaso M, Marozio M, Acaia B, Vicini R, et al. Progestogens for maintenance tocolysis in women with a short cervix: a randomized controlled rrial. Obstet Gynecol 2017;130(1):64-70.

23. Shiba R, Kinutani M, Okano S, Kawano R, Kikkawa Y. Efficacy of four vaginal progesterones for luteal phase support in frozen-thawed embryo transfer cycles: A randomized clinical trial. Reprod Med Biol. 2020;19:42-49.

24. McCambridge J, Witton J, Elbourne DR. Systematic review of the Hawthorne effect: new concepts are needed to study research participation effects. J Clin Epidemiol 2014;67:267-77.

25. Shapiro G, Fraser W, Frasch, Séquin J. Psychological stress in pregnancy and preterm birth: associations and mechanisms. J Perinat Med 2013;41:631-45. 


\section{Figures}

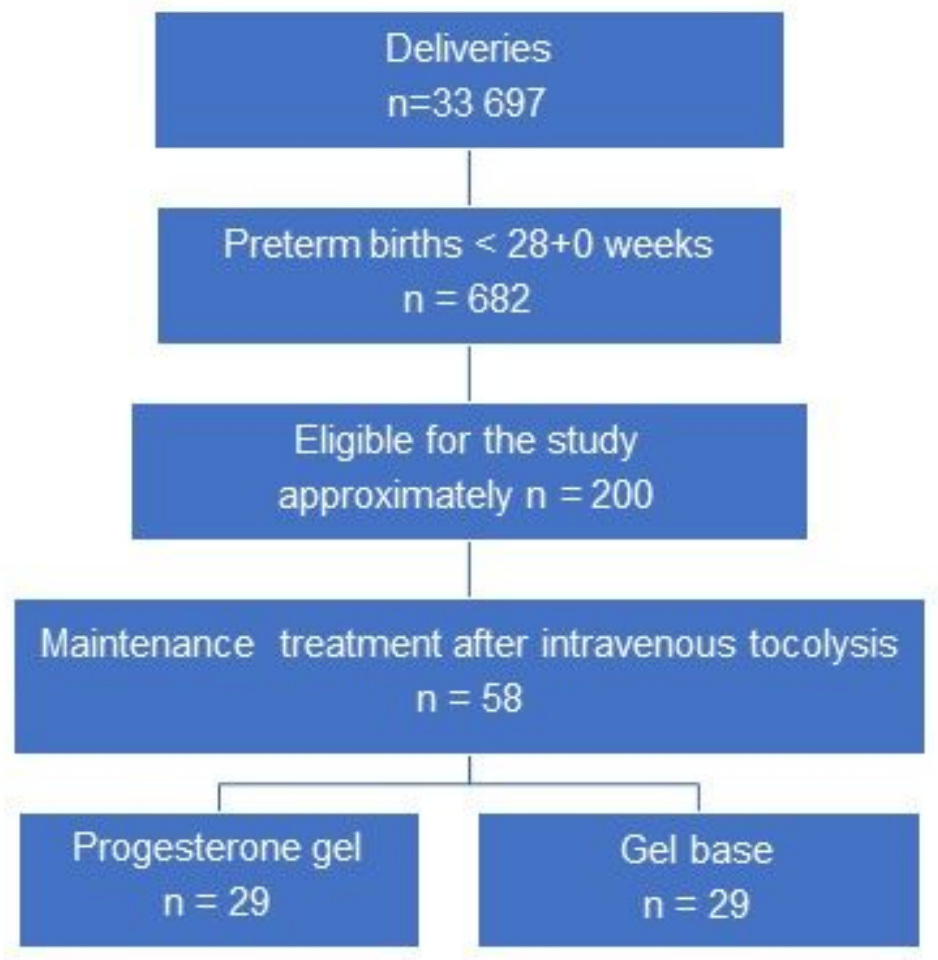

Figure 1

Patient enrolment between December 1, 2009 and January 31, 2018.

\section{Supplementary Files}

This is a list of supplementary files associated with this preprint. Click to download.

- Tables.pdf 